\title{
The Impact of Artificial Intelligence on International Trade:
} \section{Evidence From Google Neural Machine Translation}

\author{
Christina Tay, Chinese Culture University, Taiwan
}

\begin{abstract}
This paper investigates the impact of artificial intelligence on international trade. The authors use data on neural machine translation and search engines dominating domestic markets from 2016 to 2019, comprising 196 countries to test for their impact on international trade. Three variations of international trade are used: (1) manufacturing trade (sum of manufacturing exports and imports), (2) manufacturing export, and (3) manufacturing import. They cross-breed artificial intelligence theories with that of international economics. They find that artificial intelligence shows significant results at the $1 \%$ level for manufacturing trade, at the $10 \%$ level for manufacturing export, and at the $1 \%$ level for manufacturing import. They also find that as an increasing number of languages are introduced through neural machine learning, there is a decreased need to comprehend the language of another country, which in turn, has significant impact on all three variations of international trade. They also find that domestic search engines are increasingly dominating domestic and global market shares.
\end{abstract}

\section{KEYWORDS}

Artificial Intelligence Neural Machine Learning, Deep Learning, Domestic Search Engines, Economics, Google Translation, Gravity Model, International Trade, Neural Machine Translation, Search Engines

\section{INTRODUCTION}

In recent years, neural machine learning that uses artificial neural network has witnessed significant development and grown in such a refractory manner that is indescribable with words. Neural machine learning that has been designed in similar patterns to the neurons of a human brain, has increased fluency \& accuracy in language translation, and enabled the system itself to learn from millions of examples, in aims to provide the best solutions to many problems in image recognition, speech recognition as well as natural language processing.

Neural machine translation has been introduced as a promising approach to address the many deficiencies of machine translation systems. The public debut of Google Translate in 2006 utilized machine translation systems. In September of 2016, Google Translate fully switched to neural machine translation with the potential of addressing many shortcomings of machine translation (Sutskever, Vinyals \& Le, 2014).

By using neural machine learning or neural Artificial Intelligence, and incorporating techniques such as rewriting-based paradigms and on-device processing, neural machine translation has taken quantifiable leaps in language translation accuracy (Wu et al., 2016; Chan, 2020; Wiggers, 2020).

DOI: 10.4018/JTA.20210101.oa6

This article published as an Open Access article distributed under the terms of the Creative Commons Attribution License (http://creativecommons.org/licenses/by/4.0/) which permits unrestricted use, distribution, and production in any medium, provided the author of the original work and original publication source are properly credited. 


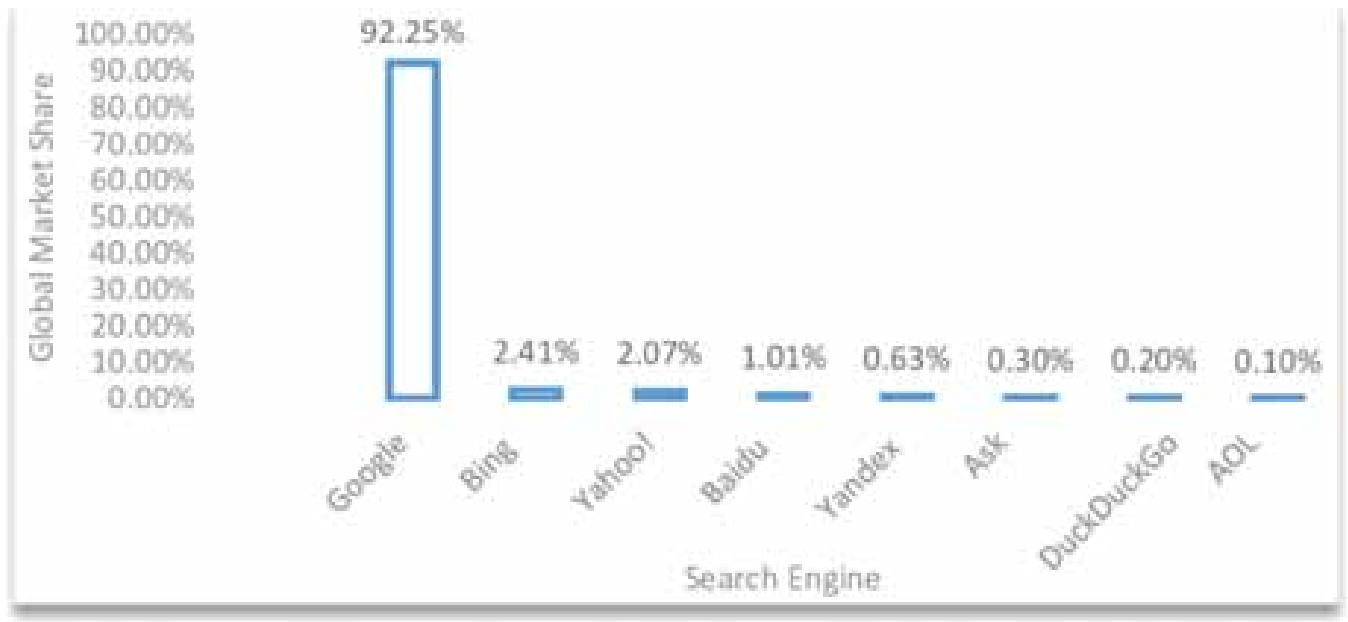

In 2016, Google Neural Machine Translation had only less than ten languages available, but this has increased to over 100 languages by 2020 (Statt, 2020).

Neural machine learning is a branch of AI that concerns the use of software to translate text from one language to another. Neural machine learning is also an end-to-end learning approach for automated translation, with the potential to overcome many of the drawbacks of conventional phrasebased translation systems (Wu et al., 2016). Although neural machine learning is still limited in some capacities, its rapid improvements and developments are contributing to an explosion of digital content, which in turn, is contributing to the rapid development of globalization including international trade.

When Google first launched its language translation service called Google Translate on April 28 of 2006 using Machine Learning (ML), it was only able to support two and hundreds of users (Turovky, 2016; Makadia, 2018). By November 2016, after Google's development of the neural machine translation system called the Google Neural Machine Translation, it is now able to support over 100 languages and has hundreds of millions of users. Google Neural Machine Translation is an artificial neural network which uses deep machine learning to mimic the functioning of a human brain and increases fluency as well as accuracy (Turovsky, 2016; Schuster et al., 2016; Wu et al., 2016; Sen, 2016; Turner, 2016). As of 2019, fourteen other languages, although are not yet supported by Google Translate, are available in the Translate Community (Translate Community, 2019).

Anecdotal evidence points towards other multilingual cyberspace in the workings including the surge of domestic search engines are dominating some countries and Google, which dominates up to $92.06 \%$ of the world market share. Such insurgence of neural machine learning technologies in the World Wide Web allows users from all tiers to "cross cyber borders" without having to comprehend a local language of that country (Philips, 2018; StatsCounter, 2020). Figure 1 shows the global market share of the world's top search engines in 2019. Microsoft's Bing take up 2.41\% of the world market share, with Yahoo! coming in third place at 2.07\%, and other search engines such as Baidu, Yandex, Ask, DuckDuckGo and AOL, dominating less than $1.01 \%$ of the world market share.

Source: StatsCounter (2020).

The rate of growth in the availability of number of languages through Google's machine translation and neural machine translation since their inauguration in 2006 and 2016, respectively, has been exponential. Initially, machine translation had fewer than 10 languages available. By 2020, it has over 100 languages, with growth and accuracy propelled by Translate Community (2020). Translate Community (2020) encourages contributors from across the world to help Google Translate improve the translation of the languages they speak, which in return, helps others understand their languages. 
Google Translate also uses a combination of machine learning \& a community of human volunteers to increase its accuracy of translation. The 100 over languages that Google Neural Machine Translation currently provides covers up to $99 \%$ of the online population (Shu, 2016).

Preliminary results of our study show that out of the 196 countries in our sample, Google's Neural Machine Translation covers up to 178 countries, or $90.8 \%$ of our sample. This coverage accounts for an official language used, a major language spoken or used, an official national language, a language taught in grade schools, a language used in courts of law, or a language used or spoken by most government officials in country.

For all the aforementioned reasons, we firmly believe that there is a strong need for empirical studies to be conducted in the area of AI, in particular, neural machine learning and tested for its impact on international trade. Thus, for the first time, to the author's knowledge, we attempt to empirically investigate a key application of AI - neural machine learning, and its impact on international trade. To date, there has been no or scant studies that has empirically tested and merged two diverging areas of studies - AI and international trade.

Thus, the purpose of our study is two-fold. First, we empirically investigate how AI impacts international trade, using Google's latest neural machine translation data from 2016 to 2019. Second, we merge two diverging strands of studies by borrowing international trade theories from economics and cross-breeding them with AI theories, and test their relevance and applicability, for the first time, using latest data on neural machine translation from 2016 to 2019 on 196 countries.

This paper is organized as follows. In the following section, we review literature on AI in the area of trade as well as its application in economics. In the third section, we present our data and methodology of which merges and cross-breeds theories of AI with that of international economics. In the fourth section, we present our empirical results and conduct robustness checks. The final section concludes and discusses our findings.

\section{LITERATURE REVIEW}

In this section, we review literature on $\mathrm{AI}$ in relation to international trade and economics. Ahhion, Benjamin \& Jones (2017), Agrawal et al. (2018), Goldfard \& Trefler (2018), Meltzer (2018) and Brynjolfsson, Hui \& Liuy (2018), are some of the latest studies on machine learning. A study by Meltzer (2018) states that although has an impact on international trade and specific applications in areas such as data analytics and translation services are reducing barriers to trade, there continues to be challenges due to the lack of global access to data.

Ahhion, Benjamin \& Jones (2017) examines the potential impact of AI on economic growth. This study models AI as the latest form of automation, dating back more than 200 years. Ahhion, Benjamin \& Jones (2017) speculates on how the automation in AI increases automation in the production of goods and services, how will it impact economic growth and how will AI affect economic growth and the division of income between labor and capital? This study finds that if some steps in the innovation process require human $\mathrm{R} \& \mathrm{D}$, then super AI may end up slowing or even ending growth by exacerbating business-stealing which in turn discourages human investments in innovation. Another finding of this study is that AI in part discourage future innovation by speeding up imitation; similarly, rapid creative destruction, by limiting the returns to an innovation, may impose its own limit on the growth process.

Agrawal et al. (2018) examines how progress in AI - a general purpose technology affects industries - focusing on advances in machine learning. They examine how a quality-adjusted drop in price impacts society and discuss how a variety of government policies are likely to influence the diffusion and consequences of AI. They conclude that diffusion-related policy categories are privacy, trade, and liability. Policy design will focus on achieving the desired balance between encouraging diffusion without compromising societal values. As AI diffuses, it will have consequences for jobs, inequality, and competition. Addressing these consequences will be the role of education policy, the social safety net, and antitrust enforcement. Goldfard \& Trefler (2018) explores the international 
dimensions of the economics of AI with respect to roles of scale, competition, and knowledge creation and knowledge diffusion. In this study, they discuss policy implications with respect to investments in research, and behind-the-border regulations such as privacy, data localization, standards, and competition. Goldfard \& Trefler (2018) conclude that there is still much to learn before we have a comprehensive understanding of how AI affects trade.

The closest strand of study to our study is that by Brynjolfsson, Hui \& Liuy (2018) who investigate the impact of machine translation on international trade. Brynjolfsson, Hui \& Liuy (2018) investigates the impact of $\mathrm{AI}$ on one internet platform, namely, eBay, which operates in 27 countries using listing attributes, product characteristics, buyer history, seller history, and reputation $\&$ feedback. They find that the introduction of a machine translation system significantly increases international trade on eBay and increases exports by $17.5 \%$. Furthermore, this study also finds that language barriers significantly hinder trade, and that AI has already begun to improve economic efficiency in at least one domain.

To close the gaps in the literature as aforementioned, we improve upon existing studies in several ways. First, the study by Meltzer (2018) states that there continues to be challenges in empirical studies due to the lack of global access to data. We address the gap in this study by attempting to conduct an empirical study based on latest data from neural machine translation from Google and test it with our revised \& augmented econometric model in international economics.

Second, the study by Goldfard \& Trefler (2018) is that it is solely a discussion paper on policy implications on the international dimensions of the economics of AI. We address the gap in this study by conducting an empirical study and testing how AI using economics theories can be tested on its effects on trade.

Third, the study by Ahhion, Benjamin \& Jones (2017) uses a modelling methodology to study the impact of AI on the economy. We improve upon this study by utilizing econometric models in international economics rather than modelling methodologies which we believe will produce more substantiated results.

Review on literatures by Ahhion, Benjamin \& Jones (2017), Agrawal et al. (2018), Goldfard \& Trefler (2018), Meltzer (2018) and Brynjolfsson, Hui \& Liuy (2018) show that the main focus of these latest studies are on machine learning. And, that the applications used in the aforementioned studies are diverse, with none, but one existing study focusing on the impact of AI on international trade. We argue that even though machine learning has dramatically increased in its predictive power in many areas such as speech recognition, image recognition, and credit scoring, we claim that machine learning is still unequitable to new AI breakthroughs in neural machine learning, in recent years (2016 - to date), which is the focus of our study.

Although Brynjolfsson, Hui \& Liuy (2018) is perhaps the first empirical study to examine the impact of machine translation and AI, in general, on international trade and industry, there are many limitations in their study. Our study builds and improves on the limitations in the study by Brynjolfsson, Hui \& Liuy (2018) in several ways.

First of all, the study by Brynjolfsson, Hui \& Liuy (2018) only investigates the impact of AI on only one internet platform, namely, eBay, which only operates in 27 countries worldwide. We improve on the study by Brynjolfsson, Hui \& Liuy (2018) by conducting an extensive study consisting of 196 countries, and base our study on dominant search engines across the world including Baidu, Bing, Sogou, Blackie, Nate, Ecoasia, Startpage, Yandex, Parsijoo, Qwant, Egerin, Swisscows, Yooz, among others.

Second of all, the study by Brynjolfsson, Hui \& Liuy (2018) concludes that language barriers significantly hinder trade. On the other hand, our study refutes their conclusion by challenging the fact that with the inauguration neural machine learning, language may no longer hinder trade. Instead, with the injection of AI in the World Wide Web, we posit that it boosts trade. We test our hypothesis empirically, for the first time, to the author's knowledge, of the impact of AI on international trade.

Third of all, the study by Brynjolfsson, Hui \& Liuy (2018) only studies the impact of machine translation on international trade, whilst our study uses neural machine translation (NML) as well as 
data on dominant search engines across the world using latest data from 2016 to 2019. In addition, we improve upon existing studies using concepts from neural machine translation in which machines can teach itself to translate text based on existing statistical models, allowing faster translations, higher quality output, and uses algorithms to learn linguistic rules on its own from statistical model.

Fourth of all, the study by Brynjolfsson, Hui \& Liuy (2018) is limited in its scope due to the idiosyncratic characteristics of the eBay digital platform design such as listing attributes, product characteristics, buyer history, seller history, reputation, feedback, among others. As a result, the results of this study maybe over-generalized due to the idiosyncratic characteristics that the eBay website possesses. We improve on this by pushing the tier of our study to a worldwide level instead of platform level. In addition, we also use three variations of international trade to test our hypothesis: (1) manufacturing trade (sum of manufacturing export and manufacturing import), (2) manufacturing export, and (3) manufacturing import.

To the author's knowledge, our study is one of the first to study a key application of AI using neural machine learning and its impact on international trade using extensive worldwide data comprising 196 countries. In this paper, we attempt to test two major two hypothesis. The first hypothesis is that due to the introduction of AI through neural machine translation tools since 2016, the impact of language could be considered a time variant factor, as more and more languages are introduced into the World Wide Web through AI, lessens the need of comprehension of a language of a user of the World Wide Web from another country. The second hypothesis is that neural machine learning can boost international trade as data and information search that previously heavily required knowledge and comprehension of a language of that country to be less significant.

To test our hypotheses, in this study, we attempt to augment and revise the gravity model of international trade by merging and cross-breeding AI theories with that of international economics. By doing so, we test and rebuke decades of robustly proven theories of international economics given the hypothesis that AI has changed the face of international trade, with neural machine translation providing strong engines of growth and advancements in the World of Wide Web, boosting international trade. This application is explained in the following section on data and methodology.

\section{DATA AND METHODOLOGY}

\subsection{Rudimentary Econometric Model of International Trade - The Gravity Model}

An important strand of international economics theory is the gravity model in the area of international trade. The gravity model has been robustly proven to be highly significant for more than seven decades since its inauguration in the 1950s. The gravity model has also made accurate predictions when Walter Isard (1952, 1954), a prominent American economist, the principal founder of the discipline of Regional Science, as well as one of the main founders of the discipline of Peace Science and Peace Economics employed it in the 1950s. Tinbergen (1962) followed Isard's footsteps and applied the gravity model to study trade flows. Linnemann (1966) then continued on the works by Tinbergen (1962), followed by Pöyhönen (1963) in the earliest studies.

To this date, the gravity model is still a widely used theory in international trade. The gravity model takes on a basic assumption that the patterns of bilateral trade between countries $\mathrm{i}$ and $\mathrm{j}$ as "proportional to the gross domestic product of two trading countries, and inversely proportional to the distance between them". A strict application of this analogy is expressed in equation (1) below, and has been used as an analogy with Newton's universal law of gravity:

$$
T_{i, j} \propto \frac{\left(G_{i}\right)^{\gamma}\left(G_{j}\right)^{\delta}}{\left(D_{i j}\right)^{\theta}}
$$


where, $\mathrm{T}_{\mathrm{ij}}$ is the bilateral trade between countries, and where, $\gamma, \delta, \theta \approx 1$. The volume of international trade between any two countries is related to the economic size of country, $\mathrm{i}$, and country, $\mathrm{j}$, represented by $\mathrm{G}_{\mathrm{i}}$ and $\mathrm{G}_{\mathrm{j}}$. $\mathrm{D}_{\mathrm{ij}}$ is the distance between the trading countries. Economic size and distance have both had strong historical roots in physics and economics in the gravity equation.

\subsection{Revision of the Econometric Model of International Trade}

Some earlier studies from the 1960s to 1990s by Tinbergen (1962), Linnemann, (1966), Pöyhönen (1963), Helpman (1988), Levine \& Renelt (1992), Mankiw, Romer \& Weil (1992), Harrison (1996), Frankel \& Romer (1996); Frankel, Jeffrey \& Romer (1996) and Hall, Glenn \& Wilcox (1996) find distance or proximity in distance between countries to have a large and overwhelmingly significant impact on bilateral trade, and that distance matters when it comes to international trade.

Later studies in the 2000s by Porojan (2001), Lewer \& Berg (2007), Malhotra, Sivakumar \& Zhu (2009), Egger \& Lassman (2012) and Tay (2014) using various international trade determinants including distance factors continue to find geographic distance to have significant and positive impact on international trade.

Since the inauguration of the internet in the 1990s, some later studies have begun to find variations of the impact of distance on international trade, with some finding puzzling, diminishing, or even defying results. According to a study by Etemad, Wilkinson \& Dana (2010), distance is found to have a diminishing role on international trade since the internet arose. Buch, Kleinert \& Toubal (2003) find that due to globalization, distance coefficients in gravity equations do not carry much information, and that the importance of distance in international trade has diminished. Tay (2020) studies and compares the impact of Information and Communication Technology between bilateral service trade and goods trade using data from the US to 34 partnering countries from 2000-2016. Using Information and Communication Technology variables and a mixture of international trade determinants including distance, Tay (2020) finds that distance does not seem to play as a significant role as found in existing studies when it comes to international trade in goods.

Based on the preliminary results of our findings in latest studies, we revise equation (1) above, and posit there to be defying effects of distance due to the rise of the internet and augmenting effects of Information and Communication Technology. Thus, we modify equation (1) to exclude the distance variable, as shown in equation (2) below:

$$
\ln T_{\mathrm{ijt}}=\beta_{0}+\beta_{1} \ln \mathrm{GDP}_{\mathrm{it}}+\beta_{2} \ln \mathrm{GDP}_{\mathrm{j} t}+\gamma_{\mathrm{i}}+\gamma_{\mathrm{j}}+\gamma_{\mathrm{t}}+\mathrm{u}_{\mathrm{ijt}}
$$

Where, $\ln \mathrm{T}_{\mathrm{ijt}}$ is our dependent variable that represents international trade. $\ln \mathrm{T}_{\mathrm{ijt}}$, in $\log$ form, is trade export/import from country, $\mathrm{i}$, to the world, $\mathrm{j}$, at time, $\mathrm{t}$, comprising of 196 countries. $\operatorname{lnGDP}_{\mathrm{it}}$ is the $\log$ of GDP per capita of country $i$, at time, $t$. $\operatorname{lnGDP}_{i t}$ is the log of GDP per capita of country, $j$, at time, t. Equation (2) presents a three-dimensional panel structure of exporting country $\left(\gamma_{\mathrm{i}}\right)$, importing $\operatorname{partner}\left(\gamma_{\mathrm{j}}\right)$, time-specific effects $\left(\gamma_{\mathrm{t}}\right)$ and random disturbance variable $\left(\mathrm{u}_{\mathrm{ijt}}\right)$

\subsection{Inclusion of Dummy Variables}

Endoh (1999) is one of the earliest studies to introduce dummy variables into the rudimentary specification of the gravity model of international trade. Endoh (1999) includes dummy variables such as common language, intra-member, inter-member trade and trade with non-members. Since Endoh (1999), other authors such as Rose (2000), Feenstra et al (2001), Sapir (2001), Martinez (2003), Melitz (2007), Kien (2009), Hejazi \& Ma (2011), Montobbio \& Sterzi (2013), Shujaat \& Waheed (2015) and Azu (2019) have also included common language into their studies. To date, the role of the common language has been strongly understood and remain robust when introduced into the gravity model.

Since Endoh's (1999) introduction of dummy variables into the basic gravity model in international trade such as the common language, the latter variable has always remained a "silently" unchallenged 
variable that is invariant to time effects. Furthermore, it has been consistently found to be statistically significant in almost, if not, all international trade studies. Typically, common language is an identifier where two countries either share an official national language or a major language spoken or used.

Equation (3) below takes on a triple-indexed model and includes a common language variable, and is presented as follows:

$$
\ln T_{\mathrm{ijt}}=\mu+\beta 1 \ln \mathrm{GDP}_{\mathrm{it}}+\beta 2 \ln \mathrm{GDP}_{\mathrm{j} t}+\beta 3 \mathrm{CL}_{\mathrm{ij}}+\gamma_{\mathrm{i}}+\gamma_{\mathrm{j}}+\gamma_{\mathrm{t}}+\mathrm{u}_{\mathrm{ijt}}
$$

Where, $\ln \mathrm{T}_{\mathrm{ijt}}$ is our dependent variable that represents international trade from/to $\mathrm{i}$, to country, $\mathrm{j}$, at time, $\mathrm{t}$, comprising a total of 196 countries. $\operatorname{lnGDP}_{i t}$ is the $\log$ of GDP per capita of country $i$, at time, t. $\operatorname{lnGDP}_{\mathrm{jt}}$ is the $\log$ of GDP per capita of country, $\mathrm{j}$, at time, t. $\mathrm{CL}_{\mathrm{ij}}$ takes the value of 1 , if two trading countries, $i$ and $j$, both share a common language, and 0 , if otherwise. $\gamma_{j}$ is the country, $\mathrm{j}$, effect; $\gamma_{\mathrm{t}}$ is the time-specific effects, where, $t=1 \ldots T$; and $\mathrm{u}_{\mathrm{ijt}}$ is a random disturbance variable.

\subsection{Augmenting Our Econometric Model With An Al Variable}

In this section, we make two hypothesis. The first hypothesis is that Neural Machine Translation technologies engineered by Google which provide worldwide internet users with simultaneous language translation tools, decreases the need for language comprehension of another culture and country, and would, thus, increase the potential for international trade. The second hypothesis is that Neural Machine Translation technology decreases the importance of traditional international trade determinants such as common language between two trading partners.

In this section, we attempt to revise and augment our econometric model by cross-breeding AI theories with that of international economics. To do so, we revise the traditional international economics theory that common language between two trading partners to be a time invariant factor given the fact that with the inauguration of neural machine learning, the common language variable should not be treated as a time invariant variable. Therefore, we test for the first time, as to how the common language variable in the gravity model can be included and treated as a time variant binary variable.

Equation (4) estimates how the impact of a key application of AI, in particular, neural machine learning, can change the (1) behavior and patterns of international trade, and (2) course of international trade theories:

$\ln T_{\mathrm{ijt}}=\beta_{0}+\beta_{1} \ln \mathrm{G}_{\mathrm{it}}+\beta_{2} \ln \mathrm{G}_{\mathrm{jt}}+\beta_{3} \mathrm{GNMT} \mathrm{CL}_{\mathrm{it}}+\gamma_{\mathrm{i}}+\gamma_{\mathrm{j}}+\gamma_{\mathrm{t}}+\mathrm{u}_{\mathrm{ijt}}$

Where, GNMT-CL $\mathrm{it}_{\mathrm{it}}$ is our AI variable. As a measurement of AI, we use language data from Google's neural machine translation. If country, $i$, uses Google's neural machine translation that contains a language that coincides with the official language, $i$, that is used in that country, then we assign a value of 1 , which otherwise assumes a value of $0 . \gamma_{j}$ is the country, $j$, effect; $\gamma_{t}$ is the timespecific effects, where, $t=1 \ldots T$; and $\mathrm{u}_{\mathrm{ijt}}$ is a random disturbance variable.

$\ln \mathrm{T}_{\mathrm{ijt}}$ is our dependent variable, and used to represent international trade. $\ln \mathrm{T}_{\mathrm{ijt}}$, in $\log$ form, is international trade from/to country, $\mathrm{i}$, to/from country, $\mathrm{j}$, at time, $\mathrm{t}$, comprising a total of 196 countries. $\operatorname{lnG}_{\mathrm{it}}$ is the Gross Domestic Product of country, $\mathrm{i}$, at time, t. $\operatorname{lnGWP}_{\mathrm{jt}}$ is the log of Gross World Product of the world, $\mathrm{j}$, in nominal prices (in billions, of US dollars), at time, $\mathrm{t}$.

The measurement used for international trade is merchandise export/import value indices (in millions, US dollar) from/to country, i, to/from worldwide, j, from 2016 to 2019. Data on international trade is obtained from the WTO data portal and the compilation of international merchandise trade statistics relies principally on customs records complemented, as appropriate, by additional sources to enhance their coverage (for instance, to include electricity, or trade in vessels and aircrafts). These statistics essentially reflect the physical movement of goods across borders. To the extent possible, 
Table 1. Search engines dominating domestic market shares

\begin{tabular}{|l|l|l|}
\hline \multicolumn{1}{|c|}{ Major Search Engine } & \multicolumn{1}{|c|}{ Country } & \multicolumn{1}{c|}{ Domestic Market Share } \\
\hline Yandex & Russia & $62 \%$ \\
\hline Baidu & China & $56 \%$ \\
\hline Sogou & China & $13 \%$ \\
\hline Yahoo! & Japan & $55 \%$ \\
\hline Naver & South Korea & $80 \%$ \\
\hline Seznam & Czech Republic & $93 \%$ \\
\hline
\end{tabular}

Source: Josian, 2018.

total merchandise trade is defined according to the general trade system. It covers all types of inward and outward movement of goods through a country or territory including movements through customs warehouses and free zones (United Nations, 2010).

Data for Gross Domestic Product (GDP per capita) is obtained from the IMF (2012-2019) and calculated in current U.S. dollars per capita. Data on Gross World Product (GWP) is the combined gross national product of 193 countries in the world equals to the total global GDP (in billions of US\$). Data on GWP is obtained from the World Bank (2016-2019), projections from the IMF (2019) and StatisticsTimes (2016-2019).

Data on common language is obtained from The CIA World Factbook (2016-2019). In some countries, people speak or use a number of languages. However, in our study, we assign only one language per country in order to have all the language totals add up to the total world population using a zero-sum approach. Only one language, whether an official, a major language spoken or used, an official national language, a language taught in grade schools, a language used in courts of law, or a language used or spoken by most government officials in country, $\mathrm{i}$, will be taken into account in tallying our data for common language.

Data on the list of neural machine translation available over the years is gathered based on the languages rolled out by Google's Machine Translation system from 2016 to 2019, Google Translate (2016-2019), Translate Community (2016 to 2019), Whitney (2015), Turovsky (2016; 2017a; 2017b), Finge, (2017), Novet (2017) and Perez (2017).

\subsection{Control Variable}

In this section, we estimate the effects of dominant search engines in respective countries that do not utilize Google as their main search engine. Google claims to dominate up to $92.06 \%$ of the world market share. Apparently, there are still some countries that have created their own domestic search engines that are predominantly used in these countries. Some examples of dominant domestic search engines that are geographically limited are SAPT in Angola, Maktoob in the Arab World, and Pipilika in Bangladesh, amongst others (Philips, 2018; StatsCounter, 2019; Wikipedia, 2019).

Table 1 shows search engines in various countries that dominate domestic markets in China, Russia, Japan, South Korea and Czech Republic. Most search engines mainly dominate their domestic markets and capture less than 3\% of the global market share in search engines. For example, Baidu (China) is able to capture only up to $1.01 \%$ of the global market share, but takes up $56 \%$ of China's domestic market share in 2018. Another example is Yandex (Russia) which captures only $0.63 \%$ of the global market share and $62 \%$ of the Russian domestic market.

For the Arab World, we originally identified 23 Arab states as defined by both UNESCO and Wikipedia. We take a step further to identify countries in the Arab states that use Arabic as their official language, and merge it with data pointing to Arab states that use Maktoob, an Arabic website, as their dominant domestic website. (Wikipedia, 2011; Briney, 2018; UNESCO, 2019; Wikipedia, 
2019). However, since two Arab states do not use Arabic as their official language, we deleted Malta and Somalia from our sample. Therefore, the total number of Arab states used in our study is 19 .

Equation (5) is formulated to include our search engine control variable:

$\ln T_{\mathrm{ijt}}=\beta_{0}+\beta_{1} \ln \mathrm{G}_{\mathrm{it}}+\beta_{2} \ln \mathrm{G}_{\mathrm{jt}}+\beta_{3} \mathrm{GNMT} \mathrm{CL}_{\mathrm{it}}+\beta_{4} \mathrm{SE}_{\mathrm{it}}+\gamma_{\mathrm{i}}+\gamma_{\mathrm{j}}+\gamma_{\mathrm{t}}+\mathrm{u}_{\mathrm{ijt}}$

Where, $\mathrm{SE}_{\mathrm{it}}$ is the dominant search engine in country, $\mathrm{i}$, at time, $\mathrm{t}$. If a search engine in a country is either geographically limited or takes up a dominant domestic market share in that country, then we assign a value of 1 , which otherwise assumes a value of 0 .

Where, $\ln \mathrm{T}_{\mathrm{ijt}}$ is the trade export from country, $\mathrm{i}$, to country, $\mathrm{j}$, at time, $\mathrm{t}_{\mathrm{ln}} \mathrm{ln}_{\mathrm{it}}$ is the Gross Domestic Product of country, $i$, at time, $t$. $\operatorname{lnG}_{\mathrm{jt}}$ is the log of Gross World Product (GWP) in nominal prices (in billions of US dollars) of the world, $\mathrm{j}$, at time, t. GNMT-CL $\mathrm{it}_{\mathrm{it}}$ is our AI variable in that takes into a language that is available through Google's Neural Machine translation in a language that coincides with an official language used in that country, $i$, at time, $t$, where $t=2016-2019 . \gamma_{j}$ is the country, $\mathrm{j}$, effect; $\gamma_{\mathrm{t}}$ is the time-specific effects, where, $t=1 \ldots T$; and $\mathrm{u}_{\mathrm{ijt}}$ is a random disturbance variable.

\subsection{Pooled Ordinary Least Squares Estimates}

We formulate separate equations using the Pooled Ordinary Least Squares methodology that take into account the impact of AI in three variations of international trade: (1) manufacturing trade - sum of manufacturing export and manufacturing import, (2) manufacturing export, and (3) manufacturing import. Thus, our dependent variable consists of three variations of international trade in manufacturing from/to country, $\mathrm{i}$ to/from the world, $\mathrm{j}$, where time, $\mathrm{t}=2016$ to 2019.

The first variation is where our dependent variable $\log \mathrm{T}_{\mathrm{i}} \leftrightarrow_{\mathrm{i}, \mathrm{t}}$ is the sum of manufacturing export and manufacturing import as represented in Equation (1) below:

$\log \mathrm{T}_{\mathrm{i}} \leftrightarrow{ }_{\mathrm{j}, \mathrm{t}=} \sum_{j=1}^{196}\left(a_{i \leftrightarrow j, t}+b_{j \leftrightarrow i, t}\right)$

Where, $\sum_{j=1}^{196}\left(a_{i \leftrightarrow j, t}+b_{j \leftrightarrow i, t}\right)$ is the sum of manufacturing export and manufacturing import from/to country, i, to/from worldwide, $\mathrm{j}$, and where time, $\mathrm{t}=2016$ to 2019 . The total number of countries is where $\mathrm{i}=1 \ldots 196$.

The second variation is where dependent variable $\log \mathrm{TE}{ }_{\mathrm{i}} \leftrightarrow_{\mathrm{j}, \mathrm{t}}$ is manufacturing export as represented in Equation (2) below:

$\log \mathrm{TE}_{\mathrm{i}} \leftrightarrow \mathrm{j}_{\mathrm{t} \mathrm{t}}=\sum_{j=1}^{196}\left(a_{i \leftrightarrow j, t}\right)$

Where, $\sum_{j=1}^{196}\left(a_{i \leftrightarrow j, t}\right)$ is the manufacturing export from/to country, i, to/from worldwide, $\mathrm{j}$, and where time, $\mathrm{t}=2016$ to 2019 . The total number of countries is where $\mathrm{i}=1 \ldots 196$.

The third variation is where our dependent variable $\log \mathrm{TI}{ }_{\mathrm{j}} \leftrightarrow_{\mathrm{i}, \mathrm{t}}$ is manufacturing import as represented in Equation (3) below:

$$
\log \mathrm{TI}_{\mathrm{j}} \leftrightarrow_{\mathrm{i}, \mathrm{t}}=\sum_{j=1}^{196}\left(b_{j \leftrightarrow i, t}\right)
$$

Where, $\sum_{j=1}^{196}\left(b_{j \leftrightarrow i, t}\right)$ is the manufacturing import from worldwide, $\mathrm{j}$, to/from worldwide, i, where time, $\mathrm{t}=2016$ to 2019 . The total number of countries is where, $\mathrm{i}=1 \ldots 196$. 
We formulate three separate equations that take into account the three variations of international trade in manufacturing: Equation (9) - manufacturing trade (sum of manufacturing export and manufacturing import), Equation (10) - manufacturing export, and Equation (11) - manufacturing import.

Equation (9) estimates the impact of AI and international trade in manufacturing as follows:

$$
\begin{aligned}
& \sum_{j=1}^{196}\left(a_{i \leftrightarrow j, t}+b_{j \leftrightarrow i, t}\right)=\beta_{0}+\beta_{1} \ln \mathrm{G}_{\mathrm{it}}+\beta_{2} \ln \mathrm{G}_{\mathrm{it}}+\beta_{3} \mathrm{GNMT}^{\mathrm{C}} \mathrm{CL}_{\mathrm{it}} \\
& +\beta_{4} \mathrm{SE}_{\mathrm{it}}+\gamma_{\mathrm{i}}+\gamma_{\mathrm{j}}+\gamma_{\mathrm{t}}+\mathrm{u}_{\mathrm{ijt}}
\end{aligned}
$$

Where, $\sum_{j=1}^{196}\left(a_{i \leftrightarrow j, t}+b_{j \leftrightarrow i, t}\right)$ is the logarithm used to represent the manufacturing trade (sum of manufacturing export and manufacturing import), from/to country, i, to/from country, $\mathrm{j}$, at time, t. follows:

Equation (10) estimates the impact of $\mathrm{AI}$ and international trade in manufacturing export as

$$
\sum_{j=1}^{196}\left(a_{i \leftrightarrow j, t}\right)=\beta_{0}+\beta_{1} \ln \mathrm{G}_{\mathrm{it}}+\beta_{2} \ln \mathrm{G}_{\mathrm{jt}}+\beta_{3} \mathrm{GNMT} \mathrm{CL}_{\mathrm{it}}+\beta_{4} \mathrm{SE}_{\mathrm{it}}+\gamma_{\mathrm{i}}+\gamma_{\mathrm{j}}+\gamma_{\mathrm{t}}+\mathrm{u}_{\mathrm{ijt}}
$$

Where, $\sum_{j=1}^{196}\left(a_{i \leftrightarrow j, t}\right)$ is the logarithm used to represent the manufacturing export from/to country, $\mathrm{i}$ to/from country, $\mathrm{j}$ in time, $\mathrm{t}$.

Equation (11) estimates the impact of $\mathrm{AI}$ and international trade in manufacturing import as follows:

$$
\sum_{j=1}^{196}\left(b_{j \leftrightarrow i, t}\right)_{=} \beta_{0}+\beta_{1} \ln \mathrm{G}_{\mathrm{it}}+\beta_{2} \ln \mathrm{G}_{\mathrm{jt}}+\beta_{3} \mathrm{GNMT}-\mathrm{CL}_{\mathrm{it}}+\beta_{4} \mathrm{SE}_{\mathrm{it}}+\gamma_{\mathrm{i}}+\gamma_{\mathrm{j}}+\gamma_{\mathrm{t}}+\mathrm{u}_{\mathrm{ijt}}
$$

Where, $\sum_{j=1}^{196}\left(b_{j \leftrightarrow i, t}\right)$ is the logarithm used to represent the manufacturing export from/to country, $\mathrm{i}$ to/from country, $\mathrm{j}$ in time, $\mathrm{t}$.

\section{EMPIRICAL RESULTS}

Tables $2 \mathrm{a}, 2 \mathrm{~b}$ and $2 \mathrm{c}$ shows the results of our Pearson correlation coefficients. All the coefficients in Table $2 \mathrm{a}, 2 \mathrm{~b}$ and $2 \mathrm{c}$ show a positive relationship between each other, except for GNMT-CL $\mathrm{L}_{\mathrm{it}}$, our AI variable in that takes into a language that is available in country, $i$, that coincides with the official language used in that country, at time, $\mathrm{t}$; and $\mathrm{SE}_{\mathrm{it}}$, our dominant search engine in country, $\mathrm{i}$, at time, t. We can observe in all Tables $2 \mathrm{a}, 2 \mathrm{~b}$ and $2 \mathrm{c}$, there is a negative relationship between these two variables. One implication of this is that as the reliance or availability of neural machine translation increases through Google, the reliance of dominant search engines in domestic countries decreases.

Another implication of this finding is that dominant search engines in domestic countries are likely to have an eclipse impact on Google's neural machine translation. When domestic countries have a local search engine available, their reliance on local/domestic search engines is more likely. Domestic search engines in their respective countries cater towards their own domestic needs and are in local languages. Our results mirror our hypothesis that dominant domestic search engines have 
Table 2. a - Correlation coefficients for total trade (Sum of manufacturing export and manufacturing import)

\begin{tabular}{|l|l|l|l|l|l|}
\hline & \multicolumn{1}{|c|}{$\mathbf{T}_{\mathrm{ijt}}$} & \multicolumn{1}{c|}{$\mathbf{G D P}_{\mathrm{it}}$} & \multicolumn{1}{c|}{$\mathbf{G W P}_{\mathrm{jt}}$} & \multicolumn{1}{c|}{$\mathbf{G N M T} \mathbf{C L}_{\mathrm{it}}$} & $\mathbf{S E}_{\mathrm{it}}$ \\
\hline $\mathrm{T}_{\mathrm{ijt}}$ & 1.000 & & & & \\
\hline $\mathrm{GDP}_{\mathrm{it}}$ & 0.511 & 1.000 & & & \\
\hline $\mathrm{GWP}_{\mathrm{jt}}$ & -0.024 & 0.039 & 1.000 & & \\
\hline GNMT-CL $_{\mathrm{it}}$ & 0.060 & 0.047 & 0.400 & 1.000 & \\
\hline $\mathrm{SE}_{\mathrm{it}}$ & 0.395 & 0.224 & 0.001 & -0.064 & 1.000 \\
\hline
\end{tabular}

(a) $T_{\mathrm{ijt}}$ is the total export and total import from country, i, to the world, j, at time, t.

(b) GDP it the gross domestic product of country, i, at time, t.

(c) GWP is the gross world product of the world, j, at time, t.

(d) GNMT- $\mathrm{CL}_{\mathrm{it}}$ is an Al variable in that takes into a language that is available in country, i, that coincides with the official language used in that country, at time, t.

(e) $\mathrm{SE}_{\mathrm{it}}$ is a dominant search engine in country, i, at time, t.

geographic tendencies. For example the SAPT search engine used in Angola, the Maktoob search engine that is commonly used in the Arab World, and the Pipilika search engine that caters to the Bangladesh population.

Our next step is to estimate our econometric models using the Ordinary Least Squares method. Initially, the observations are pooled for manufacturing trade (sum of manufacturing export and manufacturing import), manufacturing export, and manufacturing import. The results of our regression estimations for the impact of AI on international trade using three variations of international trade: (1) manufacturing trade (sum of manufacturing export and manufacturing import), (2) manufacturing export, and (3) manufacturing import are shown in Table 3.

Coefficients of determination $\left(R^{2}\right)$ are $0.594,0.368$ and 0.547 for manufacturing trade (sum of manufacturing export and manufacturing import), manufacturing export, and manufacturing import, respectively. Our models are able to explain up to $59.4 \%$ of the variation in manufacturing trade (sum of manufacturing export and manufacturing import), $36.8 \%$ of the variation in manufacturing export, and $54.7 \%$ in manufacturing import.

We find that GDP have highly positive and significant impacts, at significance levels of $0.01 \%$ for all three variations of international trade including manufacturing trade (sum of manufacturing export and manufacturing import), manufacturing export, and manufacturing import. GDP is

Table 2. b - Correlation coefficients for trade export (manufacturing export)

\begin{tabular}{|c|c|c|c|c|c|}
\hline & $\mathbf{T E}_{\mathrm{ijt}}$ & GDP $_{\text {it }}$ & $\mathbf{G W P}_{\mathrm{jt}}$ & GNMT-CL $_{\text {it }}$ & $\mathrm{SE}_{\mathrm{it}}$ \\
\hline $\mathrm{TE}_{\mathrm{ijt}}$ & 1.000 & & & & \\
\hline $\mathrm{GDP}_{\mathrm{it}}$ & 0.247 & 1.000 & & & \\
\hline $\mathrm{GWP}_{\mathrm{jt}}$ & 0.233 & 0.039 & 1.000 & & \\
\hline GNMT-CL $_{\mathrm{it}}$ & 0.144 & 0.047 & 0.400 & 1.000 & \\
\hline $\mathrm{SE}_{\mathrm{it}}$ & 0.194 & 0.224 & 0.001 & -0.064 & 1.000 \\
\hline
\end{tabular}

(a) $\mathrm{TE}_{\mathrm{it}}$ is the total export from country, i to the world, $j$, at time, t.

(b) $G D P_{i t}$ is the gross domestic product of country, i, at time, t.

(c) GWP is the gross world product of the world, j, at time, t.

(d) GNMT- $\mathrm{CL}_{\mathrm{t}}$ is an Al variable in that takes into a language that is available in country, i, that coincides with the official language used in that country, at time, $\mathrm{t}$.

(e) $\mathrm{SE}_{\mathrm{it}}$ is a dominant search engine in country, i, at time, t. 
Table 2. c - Correlation coefficients for trade import (manufacturing import)

\begin{tabular}{|c|c|c|c|c|c|}
\hline & $\mathbf{T I}_{\mathrm{jit}}$ & GDP $_{\text {it }}$ & $\mathbf{G W P}_{\mathbf{j t}}$ & GNMT-CL $_{\mathrm{it}}$ & $\mathbf{S E}_{\mathrm{it}}$ \\
\hline $\mathrm{TI}_{\mathrm{jit}}$ & 1.000 & & & & \\
\hline $\mathrm{GDP}_{\mathrm{it}}$ & 0.477 & 1.000 & & & \\
\hline $\operatorname{GWP}_{\mathrm{jt}}$ & -0.021 & 0.039 & 1.000 & & \\
\hline GNMT-CL $_{\mathrm{it}}$ & 0.059 & 0.047 & 0.403 & 1.000 & \\
\hline $\mathrm{SE}_{\mathrm{it}}$ & 0.343 & 0.199 & 0.001 & -0.061 & 1.000 \\
\hline
\end{tabular}

(a) $\mathrm{TI}_{\mathrm{jit}}$ is the total import from country, j, to country, i, at time, t.

(b) GDP is the gross domestic product of country, i, at time, $t$

(c) GWP is the gross world product of the world, j, at time, t.

(d) GNMT- $\mathrm{CL}_{\mathrm{it}}$ is an Al variable in that takes into a language that is available in country, i, that coincides with the official language used in that country, at time, t.

(e) $\mathrm{SE}_{\mathrm{it}}$ is a dominant search engine in country, i, at time, $\mathrm{t}$

highly significant at the $0.01 \%$ levels for manufacturing trade (sum of manufacturing export and manufacturing import), manufacturing export, and manufacturing import, respectively.

The results for Gross World Product is negative and significant at the 5\% level for manufacturing trade (sum of manufacturing export and manufacturing import), GWP is positive and significant at the $0.01 \%$ level for manufacturing export, and GWP is negative and significant at the $5 \%$ level for manufacturing import. This shows that the world's gross world product is also an essential determinant of international trade in all variations of trade: (1) manufacturing trade (sum of manufacturing export and manufacturing import), (2) manufacturing export, and (3) manufacturing import.

Neural Machine Learning, or AI (GNML-CL) shows positive and significant results at the $1 \%$ level for manufacturing trade (sum of manufacturing export and manufacturing import), positive and significant results at the $10 \%$ level for manufacturing export, and positive and significant results at the $1 \%$ level for manufacturing import.

Dominant search engine variable is positive and highly significant at the $0.01 \%$ level for all three variations of international trade including manufacturing trade (sum of manufacturing export and manufacturing import), manufacturing export, and manufacturing import. This shows that the existence of dominant search engines is a critical growth engine for international trade in a home country.

Overall, the economic health and wealth of a country play highly significant factors on international trade including manufacturing trade (sum of manufacturing export and manufacturing import), manufacturing export, and manufacturing import, at $0.01 \%$ levels. The overall world economy also plays a significant factor when it comes to international trade, except that its impact is greater for manufacturing export than manufacturing import.

Our results show that neural machine translation and search engines, applications of AI to have significant impact on international trade. Domestic search engines have a higher impact level than Google's Neural Machine Translation on international trade, even though both have positive and significant impacts on three variations of international trade including manufacturing trade (sum of manufacturing export and manufacturing import), manufacturing export, and manufacturing import.

Google's Neural Machine Translation has a greater impact on manufacturing imports than manufacturing exports, significant at $1 \%$ and $10 \%$, respectively. This shows that neural machine learning or language translation capabilities of search engines play a more important role for imports than exports.

In addition, this study rebukes the theory that the language variable is invariant to time. We have tested and proven that the language variable in international economics is not time invariant, which rebukes, for the first time, theories in international economics. 
Table 3. Ordinary least squares regression results

\begin{tabular}{|c|c|c|c|}
\hline Models & (a) & (b) & (c) \\
\hline Dependent variables & $\begin{array}{l}\text { Log } \\
\text { (total trade) }\end{array}$ & $\begin{array}{l}\text { Log } \\
\text { (trade export) }\end{array}$ & $\begin{array}{l}\text { Log } \\
\text { (trade import) }\end{array}$ \\
\hline (a) $\log \left(\mathrm{GDP}_{\mathrm{it}}\right)$ & $0.696(14.242)^{* * * *}$ & $\begin{array}{l}24655.06 \\
(5.640)^{* * * * *}\end{array}$ & $\begin{array}{l}0.756 \\
(13.189) * * * *\end{array}$ \\
\hline (b) $\log \left(G_{W} P_{j t}\right)$ & $\begin{array}{l}-3.385 \\
(-2.237)^{* *}\end{array}$ & $\begin{array}{l}673695.98 \\
(5.221)^{* * * * *}\end{array}$ & $\begin{array}{l}-3.541 \\
(-2.073)^{* *}\end{array}$ \\
\hline (c) $\log \left(\mathrm{GNML}-\mathrm{CL}_{\mathrm{ijt}}\right)$ & $\begin{array}{l}0.458 \\
(2.703)^{* * * *}\end{array}$ & $\begin{array}{l}25707.76 \\
(1.695)^{*}\end{array}$ & $\begin{array}{l}0.488 \\
(2.431)^{* * * *}\end{array}$ \\
\hline (d) $\log \left(\mathrm{SE}_{\mathrm{ijt}}\right)$ & $\begin{array}{l}1.567 \\
(9.714)^{* * * * *}\end{array}$ & $\begin{array}{l}61315.10 \\
(4.251)^{* * * *}\end{array}$ & $\begin{array}{l}1.627 \\
(8.235)^{* * * * *}\end{array}$ \\
\hline Constant & $\begin{array}{l}41.611 \\
(2.557)^{* * *}\end{array}$ & $\begin{array}{l}-7828410.30 \\
(-5.387)^{* * * *}\end{array}$ & $\begin{array}{l}41.848 \\
(2.172)^{* *}\end{array}$ \\
\hline Adjusted $\mathrm{R}^{2}$ & 0.594 & 0.368 & 0.547 \\
\hline No. of countries & 196 & 196 & 196 \\
\hline No. of observations & 714 & 714 & 718 \\
\hline Durbin Watson & 2.109 & 1.999 & 1.999 \\
\hline F-test & 96.610 & 27.797 & 75.923 \\
\hline VIF values & $\begin{array}{l}\text { (a) } 1.057 \\
\text { (b) } 1.192 \\
\text { (c) } 1.200 \\
\text { (d) } 1.059\end{array}$ & $\begin{array}{l}\text { (e) } 1.057 \\
\text { (f) } 1.192 \\
\text { (g) } 1.200 \\
\text { (h) } 1.059\end{array}$ & $\begin{array}{l}\text { (a) } 1.045 \\
\text { (b) } 1.195 \\
\text { (c) } 1.202 \\
\text { (d) } 1.047\end{array}$ \\
\hline \multicolumn{4}{|c|}{ 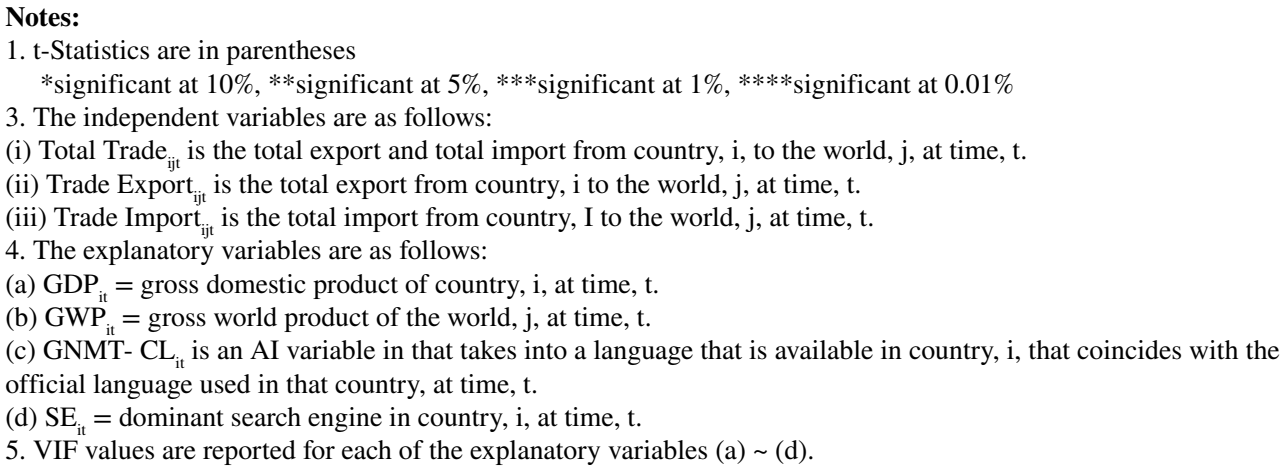 } \\
\hline
\end{tabular}

We test for heterogeneity for our models using the VIF and Durbin-Watson tests. There are no signs of multicollinearity since all our VIF values are between 1.169 and 7.689. Our second test for multicollinearity using the Durbin-Watson test also shows no signs of heterogeneity since all our values are less than 2.50 (1.999 to 2.109).

\section{DISCUSSION \& CONCLUSION}

This study investigates the impact of two key applications of AI on international trade: (1) neural machine translation, and (2) dominant domestic search engines. The results of our study show that AI has a significant impact on international trade on all three variations of trade. For neural machine learning, our first AI proxy, the results of our study shows positive and significant results at the $1 \%$ 
level for manufacturing trade (sum of manufacturing export and manufacturing import), positive and significant results at the $10 \%$ level for manufacturing export, and positive and significant results at the $1 \%$ level for manufacturing import. For dominant domestic search engines, our second artificial intelligent proxy, we find it to be positive and highly significant at the $0.01 \%$ level for all three variations of international trade including manufacturing trade (sum of manufacturing export and manufacturing import).

In this study, we have three major findings. First, as the reliance or availability of neural machine translation increases through Google, the reliance of dominant search engines in domestic countries decreases. Second, expansion efforts of dominant search engines in domestic countries is very likely to have a diminishing impact on world popular search engines such as Google. Third, if there is a domestic search engine in a host country, there is more likelihood of that country to rely on their local search engines. Fourth, the existence of dominant search engines is a critical growth engine for international trade in a home country whether in terms of the manufacturing or non-manufacturing sectors.

Our findings also have several implications, First, when neural machine learning, a key application of AI is impregnated into the World Wide Web, users from all tiers are able to "tap into" previously incomprehensible dimensions on the World Wide Web and "cross cyber borders" without having to comprehend a language of another country. With multilingualism available through the World Wide Web through neural machine translation technologies, previously complex and high costs of communications \& transportation can now be significantly reduced. Second, implication of the findings of our study is that we foresee the growing power of AI on the World Wide Web in boosting international trade to an even higher level when the AI technologies improve in the future, and when the reliance of human comprehension of languages of another country, among other important variables of international trade can be overtaken, substituted and immersed through AI into the World Wide Web. Third, we find that the merger of theories and concepts between AI and international trade \& economics can be cross-bred, and that results of the impact of AI on international trade are significant across all the variables used in our study. One implication of the findings of this study is that econometric models in international trade \& economic studies can be applied to empirical studies in AI when researchers are able to compile and search for relevant data that could be immersed into the econometric models such as that used in this study.

There are some limitations in our study. First, this study does not take into consideration service trade. Future studies could address such shortcomings by taking into account the impact of AI on service trade. Second, this study only took into account data on a worldwide basis, which may not be applicable to certain regions or countries. Future studies could take into account AI at a regional level.

In conclusion, over the coming years, as more and more languages are introduced into the World Wide Web through AI, there may be a lessened need to comprehend the language of another country when one is in cyberspace. We foresee that, this in turn, would increase transactions in international trade to a further extent. 


\section{REFERENCES}

Aghion, P., Benjamin, F., \& Jones, C. I. (2017). AI and Economic Growth. NBER Working Paper No. 23928, October 2017, JEL No. O3, O4.

Agrawal, A., \& Gans, J., \& Goldfarb. (2019). Economic Policy for AI. Innovation Policy and the Economy, 19, 139-159. doi:10.1086/699935

Anderson, J. E. (2010). The gravity model, Annual Review of Economics. Annual Reviews, 3(1), 133-160.

Arno, C. (2013). The foreign language Internet is good for business. https://web.archive.org/web/20130407032518/ http://www.scottmclay.co.uk/foreign-language-internet-good-business

Azu, N. P. (2019). Trade realignment position in ECOWAS with gravity model. International Journal of Economic Policy in Emerging Economies, 12(2). 10.1504/IJEPEE.2019.099711

Bergstrand, J. H. (1985). The gravity equation in international trade: Some microeconomic foundations and empirical. The Review of Economics and Statistics, 67(3), 474-481. doi:10.2307/1925976

Boitet, C., Blanchon, H., Seligman, M., \& Bellynck, V. (2010). MT on and for the Web. IEEE. doi:10.1109/ NLPKE.2010.5587865

Briney, A. (2018). What are the countries that make up the Arab States? List of the countries making up the Arab World. https://www.thoughtco.com/list-of-arabstates-1435128

Brynjolfsson, E., Hui, X., \& Liuy, M. (2018). Does Machine Translation Affect International Trade? Evidence from a Large Digital Platform. MIT and NBER.

Buch, C. M., Kleinert, J., \& Toubal, F. (2003). The Distance Puzzle: On the Interpretation of the Distance Coefficient in Gravity Equations. Economics Letters. Advance online publication. doi:10.1016/j.econlet.2003.10.022

Cade, M. (2016). An Infusion of AI Makes Google Translate More Powerful than Ever. Wired. Archived September 27, 2016, https://www.wired.com/2016/09/google-claims-ai-breakthrough-machine-translation/

Chan, E. (2020). Neural Network AI is the Future of the Translation Industry. Synced. https://syncedreview. com/2020/05/20/neural-network-ai-is-the-future-of-the-translation-industry/

Davies, D. (2018). Meet the 7 Most Popular Search Engines in the World. https://www.searchenginejournal. com/seo-101/meet-search-engines

Egger, P. H., \& Toubal, F. (2016). Common Spoken Languages and International Trade. In V. Ginsburgh \& S. Weber (Eds.), The Palgrave Handbook of Economics and Language. Palgrave Macmillan. doi:10.1007/978-1137-32505-1_10

Egger, P. H., \& Lassman, A. (2012). The language effect in international trade: A meta-analysis. Economics Letters, 116(2), 221-224. doi:10.1016/j.econlet.2012.02.018

Endoh, M. (1999). Trade creation and trade diversion in the EEC, the LAFTA and the CMEA: 1960-1994. Applied Economics, 31(2), 207-216. doi:10.1080/000368499324435

Etemad, H., Wilkinson, I. F., \& Dana, L. P. (2010). Internetization as the necessary condition for internationalization in the newly emerging economy. Journal of International Entrepreneurship, 8(4), 319-342. Advance online publication. doi:10.1007/s10843-010-0062-x

Feenstra, R.C. (2001). Pricing to Market, Staggered Prices and Real Exchange Rate Persistence. Journal of International Economics, 54(2), 333-359.

Felix, A. G., Jürgen, S., \& Cummins, F. (2000). Learning to Forget: Continual Prediction with LSTM. Neural Computation, 12(10), 2451-2471. doi:10.1162/089976600300015015 PMID:11032042

Finge, R. (2017). Grote verbetering voor het Nederlands in Google Translate, Big improvement for Dutch in Google Translate, April 19, 2017. Google Netherlands Blog. (in Dutch)

Frankel, J. A., \& Romer, D. (1996). Trade and Growth: An Empirical Investigation. National Bureau of Economic Research Working Paper No. 5476. 
Frankel, J. A., Romer, D., \& Cyrus, T. L. (1996). Trade and Growth in East Asian Countries: Cause and Effect? National Bureau of Economic Research Working Paper No. 5732.

Freund, C., \& Weinhold, D. (2004). The effect of the Internet on international trade. Journal of International Economics, 62(1), 171-189. doi:10.1016/S0022-1996(03)00059-X

Goldfarb, A., \& Trefler, D. (2018). AI and International Trade. NBER Working Paper No. 24254. Available at: https://www.nber.org/papers/w24254

Google Translate. (2007-2020). List of languages available on Google Neural Machine Translation system (GNMT). https://translate.google.com/intl/en/about/languages/

Hall, A. R., Rudebusch, G. D., \& Wilcox, D. W. (1996, May). Judging Instrument Relevance in Instrumental Variables Estimation. International Economic Review, 37(2), 283-298. doi:10.2307/2527324

Harrison, A. (1996, March). Openness and Growth: A Time Series, Cross-Country Analysis for Developing Countries. Journal of Development Economics, 48(2), 419-447. doi:10.1016/0304-3878(95)00042-9

Hejazi, W., \& Ma, J. (2011). Gravity, the English language and international business. Multinational Business Review, 19(2), 152-167. doi:10.1108/15253831111149780

Helpman, E. (1988). Growth, Technological Progress, and Trade. National Bureau of Economic Research Reprint No. 1145.

International Monetary Fund (IMF). (2016-2019). https://www.imf.org/

Kanenga, H. (2016). Understanding Sino-Zambia Trade Relations: Trends, Determinants and Policy Implications. World Journal of Social Sciences and Humanities, 2(2), 52-77. doi:10.12691/wjssh-2-2-5

Kien, N. T. (2009). Gravity Model by Panel Data Approach: An Empirical Application with Implications for the ASEAN Free Trade Area. ASEAN Economic Bulletin, 26(3), 266-277. www.jstor.org/stable/41317069

Larsen, K., \& Morris, R. (2002). Trade in educational services: Trends and emerging issues. World Economy, 25(6), 849-868. doi:10.1111/1467-9701.00466

Lewer, J. J., \& Berg, H. V. (2007). Religion and International Trade: Does the Sharing of a Religious Culture Facilitate the Formation of Trade Networks? American Journal of Economics and Sociology, 66(4), 765-794. doi:10.1111/j.1536-7150.2007.00539.x

Levine, R., \& Renelt, D. (1992, September). A Sensitivity Analysis of Cross-Country Growth Regressions. The American Economic Review, 82(4), 942-963.

Le, Q. \& Schuster, M. (2016). A Neural Network for Machine Translation, at Production Scale. Google Research Blog.

Linders, G.-J., \& Groot, H. L. F. (2006). Estimation of the Gravity Eq. in the Presence of Zero Flows. Tinbergen Institute Discussion Paper No. 06-072/3.

Linnemann, H. (1966). An Econometric Study of International Trade Flows. Academic Press.

Li, F., Sheng, H., \& Weisweber, W. (2001). World Wide Web - A Multilingual Language Resource. In AsiaPacific Conference on Web Intelligence, WI 2001: Web Intelligence: Research and Development (LNAI 2198, pp. 373-378). Springer-Verlag Berlin Heidelberg.

Lipsey, R. E. (2009). Measuring international trade in services. In M. Reinsdorf \& M. J. Slaughter (Eds.), International trade in services and intangibles in the era of globalization. University of Chicago Press. https:// www.nber.org/books/rein09-1

Makadia, H. (2018). Machine Learning basics — It's your cup of tea! https://hackernoon.com/machine-learningbasics-its-your-cup-of-tea-f4baf060ace

Malhotra, S., Sivakumar, K., \& Zhu, P. (2009). Distance factors and target market selection: The moderating effect of market potential. International Marketing Review, 26(6), 651-673. doi:10.1108/02651330911001332

Mankiw, N. G., Romer, D., \& Weil, D. N. (1992, May). A Contribution to the Empirics of Economic Growth. The Quarterly Journal of Economics, 107(2), 407-437. doi:10.2307/2118477 
Mapcrow. (2019). Distance calculator between cities. https://www.mapcrow.info/distance

Martinez-Z, I. (2003). Gravity model: An application to trade between regional blocs. Atlantic Economic Journal, 31(2), 174-187. doi:10.1007/BF02319869

Meltzer, J. P. (2018). The impact of AI on international trade. Center of Technology Innovation at Brookings Institution. https://www.hinrichfoundation.com/media/2bxltgzf/meltzerai-and-trade_final.pdf

Montobbio, F., \& Sterzi, V. (2013). The Globalization of Technology in Emerging Markets: A Gravity Model on the Determinants of International Patent Collaborations. World Development, 44, 281-299.

Mullainathan, S., \& Spiess, J. (2017). Machine learning: An applied econometric approach. The Journal of Economic Perspectives, 31(2), 87-106. doi:10.1257/jep.31.2.87

Novet, J. (2017). Google now provides AI-powered translations for Arabic and Hebrew, March 30, 2017. VentureBeat..

OECD. (2016-2019). Organization for Economic Development and Co-operation. https://stats.oecd.org/index. aspx?queryid $=60702$

Perez, S. (2017). Google's smarter, A.I.-powered translation system expands to more languages. In TechCrunch. Oath Inc.

Phillips, J. (2018). The top 10 international search engines. https://www.brightlines.co.uk/top-10-internationalsearch-engines/

Pöyhönen, P. (1963) A Tentative Model for the Volume of Trade between Countries. Weltwirtschaftliches Archiv, 90, 93-100. http://www.jstor.org/stable/40436776

Porojan, A. (2001). Trade Flows and Spatial Effects: The Gravity Model Revisited. Open Economies Review, 12(3), 265-280. doi:10.1023/A:1011129422190

Ravenstein, E. G. (1889, June). The Laws of Migration. Journal of the Royal Statistical Society, 52(2), 241-305. doi: $10.2307 / 2979333$

Rose, A. (2000). One money, one market: Estimating the effect of common currencies on trade. Economic Policy, 30(30), 7-45. doi:10.1111/1468-0327.00056

Sapir, A. (2001). Domino effects in Western European trade, 1960-92, ULB Institutional Repository. ULB Universite Libre de Bruxelles.

Schuster, M., Johnson, M. \& Thorat, N. (2016). Zero-Shot Translation with Google's Multilingual Neural Machine Translation System. Google Research Blog.

Sen, D. (2016). Google Translate Celebrates 10th Birthday: Here Are Some Interesting Facts about the Digital Linguist. https://www.techtimes.com/articles/155051/20160501/google-translate-celebrates-10th-birthday-hereare-some-interesting-facts-about-the-digital-linguist.htm

Sepp, H., \& Jürgen, S. (1997). Long short-term memory. Neural Computation, 9(8), 1735-1780. doi:10.1162/ neco.1997.9.8.1735 PMID:9377276

Shu, C. (2016). Google Translate now has more than 100 languages and covers 99 percent of the online population. TechCrunch. https://techcrunch.com/2016/02/17/google-translate-hits-100-languages/2016/02/17/ google-translate-hits-100-languages/

Statscounter. (2016-2020). Search Engine Market Share Worldwide. https://gs.statcounter.com/search-enginemarket-share

Statista. (2016-2019). Most common languages used on the internet, by number of speakers (in millions). https:// www.statista.com/statistics/737404/users-of-the-most-common-languages-online/

Statista. (2020). Market share of search queries handled by leading U.S. search engine providers. https://www. statista.com/statistics/267161/market-share-of-search-engines-in-the-united-states/

Statistics Times. (2016-2019). Gross World Product. http://statisticstimes.com/economy/gross-world-product.php 
Statt, N. (2020). Google Translate supports new languages for the first time in four years, including Uyghur. https://www.theverge.com/2020/2/26/21154417/google-translate-new-languages-support-odia-tatar-turkmenuyghur-kinyarwanda

Shujaat, A., \& Abdul Waheed, A. (2015). Pakistan's potential export flow: The gravity model approach. Journal of Developing Areas, 49(4), 367-378. doi:10.1353/jda.2015.0135

Sutskever, I., Vinyals, O., \& Le, Q. V. (2014). Sequence to sequence learning with neural networks. Advances in Neural Information Processing Systems, 3104-3112.

Tay, C. (2014). An econometric model on bilateral trade in education using an augmented gravity model. Journal of Industrial Engineering and Management, 7(2), 401-412. doi:10.3926/jiem.1009

Tay, C. (2015). The impact of the internet on trade in education. Technological and Economic Development of Economy, 21(6), 833-854. doi:10.3846/20294913.2015.1108941

Tay, C. (2020). Comparison of the Impact of ICT between Bilateral Trade in Goods and Services, Journal of System and Management Sciences, 10(1), 1-31.

The CIA World Factbook. (2016-2019). The Central Intelligence Agency. https://www.bartleby.com/151/a37.html

The World Bank. (2016-2019). Percentage of population that has internet access. https://databank.worldbank. org/data/reports.aspx ?source=2\&series=IT.NET.USER.ZS\& country=BGD,IND\#

Tinbergen. (1962). Shaping the World Economy: Suggestions for an International Economic Policy. New York: The Twentieth Century Fund.

Community, T. (2006-2020). Translate Community: Help us improve Google Translate!<templatestylessrc=" Module:Citation/CS1/styles.css”></templatestyles $>$. https://translate.google.com/community

CommunityT. (2020). Google Translate. https://translate.google.com/intl/en/about/contribute/

Turner, K. (2016). Google Translate is getting really, really accurate. https://www.washingtonpost.com/news/ innovations/wp/2016/10/03/google-translate-is-getting-really-really-accurate/?utm_term=.3649dfc18928

Turovsky, B. (2016). Found in translation: More accurate, fluent sentences in Google Translate. The Keyword Google Blog.

Turovsky, B. (2017a). Higher quality neural translations for a bunch more languages. The Keyword Google Blog.

Turovsky, B. (2017b). Making the internet more inclusive in India, April 25, 2017. The Keyword.

UNESCO. (2016-2019). United Nations Educational, Scientific and Cultural Organization Institute of Statistics. http://stats.uis.unesco.org

UNESCO. (2019). Arab States - United Nations Educational, Scientific and Cultural Organization. http://www. unesco.org/new/en/unesco/worldwide/arab-states/

United Nations. (2010). International Merchandise Trade Statistics: Concepts and Definitions. Department of Economic and Social Affairs Statistics Division, Statistical Papers Series M No. 52, United Nations. https:// unstats.un.org/unsd/trade/eg-imts/IMTS\%202010\%20(English).pdf

Vemuri, V. K., \& Siddiqi, S. (2009). Impact of commercialization of the Internet on international trade: A panel study using the extended gravity model. The International Trade Journal, 23(4), 458-484. doi:10.1080/08853900903223792

W3Techs. (2016-2019). Historical yearly trends in the usage of content languages for websites. Web Technology Surveys. https://w3techs.com/technologies/history_overview/content_language/ms/y

Walter, I. (1952). Atomic Power, an Economic and Social Analysis; a Study in Industrial Location and Regional Economic Development. Blakiston.

Walter, I. (1956). Location and Space-economy; a General Theory Relating to Industrial Location, Market Areas, Land Use, Trade, and Urban Structure. Technology Press of Massachusetts Institute of Technology and Wiley. 
Whitney, L. (2015). Google Translate app adds 20 more languages for instant translation via your camera. Archived July 29, 2015, https://www.cnet.com/news/the-absolute-best-amazon-prime-day-2019-deals/

Wiggers, K. (2020). How Google is using emerging AI techniques to improve language translation quality. https:// venturebeat.com/2020/06/03/how-googleis-using-emerging-ai-techniques-to-improve-language-translationquality/

Wikipedia. (2011). Arab World. In Wikipedia, the Free Encyclopedia. https://en.wikipedia.org/wiki/Arab_world

Wikipedia. (2020). List of search engines by geographically limited scope. https://en.wikipedia.org/wiki/ List_of_search_engines

World Bank. (2016-2019). The World Bank Open Data. https://data.worldbank.org/

WTO Data Portal. (2012-2019). World Trade Organization. http://data.wto

Wu, Y., Schuster, M., Chen, Z., Quoc, V., Norouzi, M., Macherey, W., Krikun, M., Cao, Y., Gao, Q., Macherey, K., Klingner, J., Shah, A., Johnson, M., Liu, X., Kaiser, L., Gouws, S., Kato, Y., Kudo, T., Kazawa, H., . . . Jeffrey Dean, J. (2016). Google's Neural Machine Translation System: Bridging the Gap between Human and Machine Translation, October 8, 2016, Version 2. https://arxiv.org/abs/1609.08144 


\section{APPENDIX A: LIST OF COUNTRIES (196 COUNTRIES)}

Afghanistan, Albania, Algeria, American Samoa, Anguilla, Angola, Antigua and Barbuda, Argentina, Armenia, Aruba, Australia, Austria, Azerbaijan, Bahamas, Bahrain, Bangladesh, Barbados, Belarus, Belgium, Belize, Benin, Bermuda, Bhutan, Bolivia, Bosnia and Herzegovina, Botswana, Brazil, Brunei, Bulgaria, Burkina Faso, Burma (Myanmar), Burundi, Cambodia, Cameroon, Canada, Central African Republic, Chad, Chile, China, Colombia, Comoros, Congo, Democratic Republic of the Congo, Costa Rica, Croatia, Cuba, Cyprus, Czech Republic, Côte d'Ivoire, Denmark, Djibouti, Dominica, Dominican Republic, Ecuador, Egypt, El Salvador, Equatorial Guinea, Eritrea, Estonia, Ethiopia, Falkland Islands (Islas Malvinas), Faroe Islands, Fiji, Finland, France, French Guiana, Gabon, Gambia, The Gaza Strip, Georgia, Germany, Ghana, Gibraltar, Greece, Greenland, Grenada, Guam, Guatemala, Guinea, Guinea-Bissau, Guyana, Haiti, Honduras, Hong Kong, Hungary, Iceland, India, Indonesia, Iran, Iraq, Ireland, Israel, Italy, Jamaica, Japan, Jordan, Kazakhstan, Kenya, Kiribati, Korea, North Korea, Korea, South, Kuwait, Kyrgyzstan, Laos, Latvia, Lebanon, Lesotho, Liberia, Libya, Liechtenstein, Lithuania, Luxembourg, Macau, Macedonia, Republic of Madagascar, Malawi, Malaysia, Maldives, Mali, Malta, Isle of Marshall Islands, Martinique, Mauritania, Mauritius, Mexico, Micronesia, Federated States of Moldova, Monaco, Mongolia, Montserrat, Morocco, Mozambique, Namibia, Nauru, Nepal, Netherlands, Netherlands Antilles, New Zealand, Nicaragua, Niger, Nigeria, Niue, Norway, Oman, Pakistan, Palau, Panama, Papua New Guinea, Paraguay, Peru, Philippines, Pitcairn Islands, Poland, Portugal, Puerto Rico, Qatar, Romania, Russia, Rwanda, Samoa, San Marino, Saudi Arabia, Senegal, Serbia and Montenegro, Seychelles, Sierra, Leone, Singapore, Slovakia, Slovenia, Solomon Islands, Somalia, South Africa, Spain, Sri Lanka, Sudan, Suriname, Sweden, Switzerland, Syria, Taiwan, Tajikistan, Tanzania, Thailand, Togo, Tokelau, Tonga, Trinidad and Tobago, Tunisia, Turkey, Turkmenistan, Turks and Caicos Islands, Tuvalu, Uganda, Ukraine, United Arab Emirates, United Kingdom, United States, Uruguay, Uzbekistan, Vanuatu, Venezuela, Vietnam, West Bank, Yemen, Zambia, Zimbabwe.

Christina Tay's published works include journals such as Association for Computing Machinery, Technological and Economic Development of Economy, International Journal of Services Operations and Informatics, International Journal of Social, Behavioral, Educational, Economic, Business and Industrial Engineering, Institute of Electrical and Electronics Engineers (IEEE), Technological and Economic Development of Economy, Journal of Applied Finance \& Banking, IFIP Advances in Information and Communication Technology, Journal of Industrial Engineering and Management, International Journal of Information and Management Sciences. 